\title{
Effect of dietary conjugated linoleic acid isomers on lipid metabolism in hamsters fed high-carbohydrate and high-fat diets
}

\author{
Elizabeth J. Tarling ${ }^{1}$, Kevin J. P. Ryan ${ }^{1}$, Andrew J. Bennett ${ }^{2}$ and Andrew M. Salter ${ }^{1}$ * \\ ${ }^{1}$ Division of Nutritional Sciences, School of Biosciences, University of Nottingham, Sutton Bonington Campus, Loughborough LE12 \\ $5 R D, U K$ \\ ${ }^{2}$ School of Biomedical Sciences, Medical School, Queen's Medical Centre, Clifton Boulevard, Nottingham NG7 2UH, UK \\ (Received 8 April 2008 - Revised 12 September 2008 - Accepted 15 September 2008 - First published online 5 November 2008)
}

Dietary conjugated linoleic acids (CLA) have been reported to have a number of isomer-dependent effects on lipid metabolism including reduction in adipose tissue deposition, changes in plasma lipoprotein concentrations and hepatic lipid accumulation. The aim of this study was to compare the effect of individual CLA isomers against lipogenic and high 'Western' fat background diets. Golden Syrian hamsters were fed a high-carbohydrate rodent chow or chow supplemented with $17.25 \%$ fat formulated to represent the type and amount of fatty acids found in a typical 'Western' diet (including $0.2 \%$ cholesterol). Diets were further supplemented with $0.25 \%$ (w/w) rapeseed oil, cis 9 , trans 11 (c9,t11)-CLA or trans10, cis12 (t10,c12)-CLA. Neither isomer had a significant impact on plasma lipid or lipoprotein concentrations. The t10,c12-CLA isomer significantly reduced perirenal adipose tissue depot mass. While adipose tissue acetyl CoA carboxylase and fatty acid synthase mRNA concentrations (as measured by quantitative PCR) were unaffected by CLA, lipoprotein lipase mRNA was specifically reduced by t10,c12-CLA, on both background diets $(P<0 \cdot 001)$. This was associated with a specific reduction of sterol regulatory element binding protein $1 \mathrm{c}$ expression in perirenal adipose tissue $(P=0.018)$. The isomers appear to have divergent effects on liver TAG content with c9,t11-CLA producing lower concentrations than t10,c12-CLA. We conclude that t10,c12-CLA modestly reduces adipose tissue deposition in the Golden Syrian hamster independently of background diet and this may possibly result from reduced uptake of lipoprotein fatty acids, as a consequence of reduced lipoprotein lipase gene expression.

Conjugated linoleic acid: Lipoprotein lipase: Sterol regulatory element binding protein: Hamster

Conjugated linoleic acid (CLA) refers to a mix of geometric and positional isomers of linoleic acid where the two double bonds are conjugated. The last decade has seen a plethora of claims, mainly supported by work with animal models, that dietary intake of CLA is associated with potential health benefits ${ }^{(1,2)}$. These include reduction in fat deposition, protection from atherosclerosis and cancer and enhanced immunity. Translation of these effects into benefits to human health has proven intractable with little evidence to support effects on CVD, immunity or cancer ${ }^{(2-4)}$. Effects on fat deposition have also been variable, with a recent metaanalysis of eighteen human trials concluding that at a dose of $3.2 \mathrm{~g} / \mathrm{d}$, consumption of mixed CLA isomers (primarily cis 9 , trans 11 (c9,t11)-CLA and trans 10 , cis 12 (t10,c12)-CLA) produces modest body fat loss in $\operatorname{man}^{(5)}$. It is of note that mixed isomers of CLA have recently been awarded Generally Regarded as Safe status by the Food and Drug Administration in the USA and can now be added to fluid and flavoured milks, yoghurts, milk-based meal replacements, meal replacement bars, soya milk and fruit juice (http://www.cognis.com/company/Press + and + Media/Press+Releases/2008/080728_EN_NH.htm).

The predominant CLA isomer in the diet is the c9,t11 isomer, which is primarily found in milk and meat of ruminant animals, and is produced from desaturation of rumenal trans$1118: 1$ through the action of stearoyl CoA desaturase in the tissues of the animal ${ }^{(6)}$. Much smaller amounts of other isomers can also be found in ruminant products. In addition to naturally occurring CLA, dietary supplements are also widely available. Until recently these have tended to be isomeric mixtures (largely equal mixtures of c9,t11-CLA and t10,c12-CLA), however more recently pure c9,t11-CLA and t10,c12-CLA have become available.

Many of the health benefits attributed to CLA have been linked to specific isomers. The t10,c12-CLA isomer is most potent in reducing body fat deposition ${ }^{(7)}$. The c9,t11-CLA isomer has been suggested to have tumoursuppressive actions ${ }^{(8)}$. Evidence for effects of individual isomers on CVD and its associated risk factors has been less conclusive $\mathrm{c}^{(2,3)}$.

Abbreviations: ABC-A1, ATP binding cassette transporter A1; ACC, acetyl CoA carboxylase; c9,t11, cis9, trans11; CLA, conjugated linoleic acid; FAS, fatty acid synthase; HF/HC, high fat/high cholesterol; LDLr, LDL receptor; LPL, lipoprotein lipase; SREBP, sterol regulatory element binding protein; t10,c12, trans 10 , cis 12. * Corresponding author: Dr Andrew M. Salter, fax + 44115 9516122, email Andrew.Salter@nottingham.ac.uk 
Much of the data currently available on the effects of CLA isomers in vivo has been gathered from studies using mice. However, it has become increasingly clear that this species shows a much greater reduction in body fat in response to CLA than most other species ${ }^{(9)}$. In recent years a number of studies have reported the comparative effects of pure CLA isomers on lipid metabolism in the Golden Syrian hamster ${ }^{(10-23)}$. While most of these have reported some degree of reduction in adipose tissue deposition, effects on plasma lipids have been less conclusive. All of these studies have tended to use high doses $(0.5 \% \mathrm{w} / \mathrm{w}$ or greater) of CLA against the background of a high-fat diet and usually substituting linoleic acid-rich oils with CLA. Such diets have often been supplemented with highly saturated plant oils containing very low concentrations of unsaturated fatty acids. In the present study we fed $0.25 \%(\mathrm{w} / \mathrm{w})$ pure c9,t11-CLA or t10,c12-CLA against a background diet of either low-fat chow or a high-fat diet designed to mimic the fatty acid composition and quantity of a typical 'Western' diet.

\section{Materials and methods \\ Protocol of animal treatment}

All procedures involving hamsters were subject to UK Home Office regulations and animals were housed as previously described $^{(14)}$. Hamsters were anaesthetized using sodium pentabarbitone (Sagatal; $1 \mathrm{ml} / \mathrm{kg}$ ) and 3-4 $\mathrm{ml}$ blood was collected by cardiac puncture and placed into EDTA-tubes. While animals were not fasted, they were killed during the light-phase (when food intake would be minimal), between the times of 09.00 and 12.00 hours. Plasma was isolated by centrifugation and stored at $4{ }^{\circ} \mathrm{C}$ until lipoprotein separation which was commenced within $48 \mathrm{~h}$ of collection. Livers and perirenal and epididymal fat pads were removed, weighed and snapfrozen in liquid nitrogen.

Experimental diets were fed for 6 weeks. Hamsters $(8-12$ weeks old) were randomly divided into seven groups of eight animals. Animals were fed either a chow diet (Rat and Mouse Diet 1; Special Diet Supplies) or the same chow supplemented with $172.5 \mathrm{~g}$ fat $/ \mathrm{kg}$ and $0.2 \%$ cholesterol (high fat/high cholesterol (HF/HC): beef tallow, $135 \mathrm{~g} / \mathrm{kg}$, tripalmitin, $15 \mathrm{~g} / \mathrm{kg}$; maize oil, $22.5 \mathrm{~g} / \mathrm{kg}$ ). Diets were prepared in $2 \mathrm{~kg}$ batches and frozen at $-20^{\circ} \mathrm{C}$ in $500 \mathrm{~g}$ aliquots until use. Rapeseed oil/CLA were added directly to ground chow. The high-fat diet was prepared by adding cholesterol to melted tallow + tripalmitin and then mixing this with chow, maize oil and rapeseed oil/CLA. Animals were fed every 2-3 d with un-eaten food being completely removed and discarded. The total fat content of the chow diet was approximately $2.8 \%$ and that of the $\mathrm{HF} / \mathrm{HC}$ was $19.4 \%$. The major fatty acids in the chow diet were $4.38 \% 14: 0,24.4 \% 16: 0$, $10.5 \% 18: 0,27.4 \% 18: 1$ and $27.9 \% 18: 2$. Those in the $\mathrm{HF} / \mathrm{HC}$ diet contained $3.21 \% 14: 0,31.4 \% 16: 0,16.7 \%$ $18: 0,28.6 \% 18: 1$ and $12.8 \% 18: 2$. Each of the diets were further supplemented with $2 \cdot 5 \mathrm{~g} / \mathrm{kg}$ of either high oleic rapeseed oil (human food grade), c9,t11 CLA (90\% c9,t11-CLA, $3.8 \%$ t10,c12-CLA, $3.3 \% \mathrm{c} 9-18: 1$ and $2.5 \%$ other conjugated isomers) or t10,c12-CLA (94.4\% t10,c12-CLA, $2.0 \%$ c9,t11-CLA, $0.4 \% \quad \mathrm{c} 9-18: 1$ and $2.9 \%$ other conjugated isomers). The rapeseed-supplemented chow and $\mathrm{HF} / \mathrm{HC}$ diets both contained approximately 0.28 and $0.24 \%$ of $\mathrm{c} 9, \mathrm{t} 11-$ CLA, respectively, and no detectable t10,c12-CLA. Supplementation with CLA increased the relative amount of the appropriate isomer to approximately 7 and $1 \%$ of the total fatty acids in the chow and $\mathrm{HF} / \mathrm{HC}$ diets, respectively. A further $\mathrm{HF} / \mathrm{HC}$ diet was supplemented with $1 \% \mathrm{t} 10, \mathrm{c} 12-$ CLA. CLA isomers were provided by Larodan Fine Chemicals AB (Malmö, Sweden). Animals had free access to food and water, and food was replaced completely every $2-3 \mathrm{~d}$. Daily food intake was measured between days 21 and 27 of the trial.

\section{Fatty acid analysis}

The fatty acid composition of perirenal adipose tissue was determined by GC of fatty acid methyl esters as previously described $^{(17)}$.

\section{Lipoprotein separation and cholesterol and TAG analysis}

After removal of TAG-rich lipoproteins (density $<1.02 \mathrm{~g} / \mathrm{ml}$ ), plasma LDL (density $=1.02-1.06 \mathrm{~g} / \mathrm{ml}$ ) and HDL (density $>1.06 \mathrm{~g} / \mathrm{ml}$ ) were isolated from hamster plasma as previously described $^{(24)}$. Total plasma cholesterol and TAG concentrations were determined using diagnostic kits from ThermoTrace (Infinity Cholesterol and Infinity TAG Enzymatic kits; Alpha Laboratories). Hepatic cholesterol and TAG concentrations were also determined using Thermo-Trace diagnostic kits.

\section{Determination of mRNA levels}

RNA was extracted from liver and perirenal adipose tissue using Trizol (Invitrogen) according to the manufacturer's instructions. Genomic DNA was digested with DNase, RNA purity and yield were determined, and RT-PCR was performed as described previously ${ }^{(25)}$. For the relative quantification of cDNA for ATP binding cassette transporter A1 (ABC-A1), acetyl CoA carboxylase (ACC), fatty acid synthase (FAS), lipoprotein lipase (LPL), LDL receptor (LDLr), sterol regulatory element binding proteins (SREBP) 1a, 1c and 2 quantitative, real-time PCR was performed using either a Prism 7700 Sequence Detector (Applied Biosystems) or a Lightcycler 480 (Roche). Primer and probe sequences and real-time PCR methods were as previously described $^{(25)}$. Standard curves were used to check assay linearity and to determine sample gene expression in RNA equivalents using the $C_{T}$ values. In addition to the genes of interest the mRNA concentrations for the housekeeping gene, $\beta$-actin, were measured and found not to differ between treatment groups. Relative expression of genes of interest were therefore normalized to $\beta$-actin and expressed as arbitrary units.

\section{Statistical analyses}

Data from control animals and those fed either $0.25 \% \mathrm{c} 9, \mathrm{t} 11$ CLA or t10,c12-CLA were analysed by two-way ANOVA, with diet as one factor and CLA as another. Results are expressed as means and the standard error of the difference. Treatment effects and differences between means were considered significant when $P<0 \cdot 05$. Where an effect of CLA 
was apparent, but no interaction with background diet, data were further analysed by post hoc Bonferoni test to determine differential effects of isomers. Selected data for animals fed 0.25 and $1 \%$ t10,c12-CLA were analysed by regression analysis to determine dose-dependent effects.

\section{Results}

\section{Effect on body composition}

The mean initial starting weight of all animals was 93.0 (SD $8.3 \mathrm{~g}$ ) with no significant differences between groups of animals. Over the course of the experiment animals gained an average of 26.2 (SD 9) g. As can be seen in Table 1, no significant difference in weight gain (expressed as a percentage of initial weight) was seen between the groups. While there was no effect of either CLA isomer on food intake, animals adapted to the higher energy density of the $\mathrm{HF} / \mathrm{HC}$ diet by reducing their food intake.
There was a significant reduction in the relative weight of the perirenal adipose tissue depot in animals fed t10,c12CLA, which was independent of background diet. Further analysis was performed on data from animals fed the $\mathrm{HF} / \mathrm{HC}$ diet supplemented with $0,0.25$ and $1 \% \mathrm{t} 10$, c12-CLA to ascertain whether the effects on perirenal adipose tissue weight were dose dependent (Fig. 1 (C)). Regression analysis failed to demonstrate a statistically significant relationship $(P=0 \cdot 094)$. By contrast to the perirenal adipose tissue depot, epididymal fat weight was not influenced by CLA feeding, even when t10,c12-CLA was fed at a level of $1 \%$ (relative weight of epididymal tissue in animals fed $1 \%$ t10,c12-CLA was 1.79 (SD 0.35) and not significantly different to values for animals fed $0 \%$ CLA or $0.25 \%$ t10,c12-CLA).

Fatty acid analysis of perirenal adipose tissue indicated that in animals fed chow, c9,t11-CLA made up 0.24 (SD 0.06) \% of total fatty acids, which increased to 0.37 (SD 0.05) \% in those fed the $\mathrm{HF} / \mathrm{HC}$ diet. Supplementation of each of these diets with $0.25 \% \mathrm{c} 9, \mathrm{t} 11-\mathrm{CLA}$ increased the content of this fatty

Table 1. Changes in body composition of hamsters fed a chow or high-fat/high-cholesterol (HF/HC) diet supplemented with $0.25 \%$ (w/w) conjugated linoleic acid (CLA) isomers (eight animals per group)*

\begin{tabular}{|c|c|c|c|c|c|c|c|c|}
\hline & & \multicolumn{4}{|c|}{ CLA } & \multicolumn{3}{|c|}{ ANOVA $†$} \\
\hline & & None & $c 9, t 11$ & $\mathrm{t} 10, \mathrm{c} 12$ & Mean & & SED & $P$ \\
\hline \multirow[t]{3}{*}{ Initial body weight $(\mathrm{g})$} & Chow & $95 \cdot 1$ & $90 \cdot 2$ & $97 \cdot 2$ & $94 \cdot 1$ & $\mathrm{D}$ & $2 \cdot 34$ & 0.355 \\
\hline & $\mathrm{HF} / \mathrm{HC}$ & $89 \cdot 2$ & $90 \cdot \overline{6}$ & $96 \cdot 0$ & 91.9 & C & $2 \cdot 87$ & 0.096 \\
\hline & Mean & $92 \cdot 1$ & $90 \cdot 4$ & $96 \cdot 6$ & 93.0 & $\mathrm{D} \times \mathrm{C}$ & 4.06 & 0.531 \\
\hline \multirow[t]{3}{*}{ Final body weight (g) } & Chow & 124.9 & $110 \cdot 9$ & $120 \cdot 2$ & $118 \cdot 7$ & D & 3.72 & 0.071 \\
\hline & $\mathrm{HF} / \mathrm{HC}$ & $114 \cdot 1$ & $118 \cdot 7$ & $127 \cdot 2$ & $120 \cdot 0$ & C & 3.03 & 0.662 \\
\hline & Mean & 119.5 & $114 \cdot 8$ & $123 \cdot 7$ & $119 \cdot 3$ & $\mathrm{D} \times \mathrm{C}$ & $5 \cdot 26$ & 0.025 \\
\hline \multirow[t]{3}{*}{ Change in body weight $(\mathrm{g})$} & Chow & 29.8 & $20 \cdot 7$ & 23.0 & 24.5 & D & 3.07 & 0.580 \\
\hline & $\mathrm{HF} / \mathrm{HC}$ & 24.9 & $28 \cdot 1$ & 31.1 & 28.0 & C & $2 \cdot 51$ & $0 \cdot 167$ \\
\hline & Mean & $27 \cdot 3$ & $24 \cdot 4$ & $27 \cdot 1$ & $26 \cdot 3$ & $D \times C$ & 4.35 & 0.067 \\
\hline \multirow[t]{3}{*}{ Daily feed intake (g) } & Chow & $7 \cdot 70$ & $6 \cdot 51$ & $6 \cdot 70$ & 6.97 & $\mathrm{D}$ & 0.38 & $<0.001$ \\
\hline & $\mathrm{HF} / \mathrm{HC}$ & $5 \cdot 75$ & 5.65 & 6.02 & $5 \cdot 80$ & $\mathrm{C}$ & 0.31 & 0.248 \\
\hline & Mean & 6.72 & 6.08 & 6.36 & $6 \cdot 39$ & $D \times C$ & 0.53 & 0.192 \\
\hline \multirow[t]{3}{*}{ Perirenal adipose weight (g) } & Chow & 2.05 & 1.50 & 1.49 & 1.68 & D & 0.16 & $0 \cdot 160$ \\
\hline & $\mathrm{HF} / \mathrm{HC}$ & 1.71 & $1 \cdot 70$ & 1.79 & 1.73 & $\mathrm{C}$ & 0.13 & 0.700 \\
\hline & Mean & 1.88 & 1.60 & 1.64 & $1 \cdot 71$ & $D \times C$ & 0.22 & $0 \cdot 106$ \\
\hline \multirow[t]{3}{*}{ Perirenal adipose weight (\% of final body wt) } & Chow & 1.61 & 1.34 & 1.24 & 1.40 & D & 0.08 & 0.712 \\
\hline & $\mathrm{HF} / \mathrm{HC}$ & 1.49 & 1.40 & 1.40 & 1.43 & C & 0.09 & 0.049 \\
\hline & Mean & $1.55^{\mathrm{a}}$ & $1.37^{\mathrm{a}, \mathrm{b}}$ & $1.32^{\mathrm{b}}$ & 1.41 & $D \times C$ & 0.13 & 0.334 \\
\hline \multirow[t]{3}{*}{ Epididymal adipose weight (g) } & Chow & 2.35 & $2 \cdot 01$ & 2.37 & $2 \cdot 24$ & $\mathrm{D}$ & 0.17 & 0.441 \\
\hline & $\mathrm{HF} / \mathrm{HC}$ & $2 \cdot 12$ & $2 \cdot 38$ & 2.43 & $2 \cdot 31$ & C & 0.14 & 0.628 \\
\hline & Mean & $2 \cdot 24$ & $2 \cdot 19$ & 2.40 & 2.28 & $D \times C$ & 0.24 & 0.231 \\
\hline \multirow{3}{*}{ Epididymal adipose weight (\% of final body wt) } & Chow & 1.86 & 1.80 & 1.97 & 1.88 & D & 0.10 & 0.718 \\
\hline & $\mathrm{HF} / \mathrm{HC}$ & 1.84 & 1.99 & 1.90 & 1.91 & C & 0.09 & 0.705 \\
\hline & Mean & 1.85 & 1.90 & 1.93 & 1.89 & $\mathrm{D} \times \mathrm{C}$ & 0.15 & 0.434 \\
\hline \multirow[t]{3}{*}{ Liver weight (g) } & Chow & $5 \cdot 25$ & 4.45 & 5.99 & $5 \cdot 23$ & $\mathrm{D}$ & 0.26 & $<0.001$ \\
\hline & $\mathrm{HF} / \mathrm{HC}$ & 5.67 & 5.98 & 6.65 & $6 \cdot 10$ & C & 0.22 & $<0.001$ \\
\hline & Mean & $5 \cdot 46^{\mathrm{a}}$ & $5 \cdot 21^{\mathrm{a}}$ & $6 \cdot 32^{\mathrm{b}}$ & 5.66 & $\mathrm{D} \times \mathrm{C}$ & 0.37 & 0.098 \\
\hline \multirow[t]{3}{*}{ Liver weight (\% of final body wt) } & Chow & $4 \cdot 19$ & 4.03 & 4.96 & 4.39 & $\mathrm{D}$ & 0.11 & $<0.001$ \\
\hline & $\mathrm{HF} / \mathrm{HC}$ & 4.99 & 4.94 & $5 \cdot 21$ & 5.04 & C & 0.14 & $<0.001$ \\
\hline & Mean & 4.59 & 4.49 & 5.08 & 4.72 & $D \times C$ & 0.19 & 0.041 \\
\hline \multirow{3}{*}{ Liver TAG ( $\mu \mathrm{mol} /$ liver) } & Chow & 4.63 & $2 \cdot 30$ & 4.11 & 3.68 & D & 0.50 & 0.005 \\
\hline & $\mathrm{HF} / \mathrm{HC}$ & 5.05 & 3.93 & 6.52 & $5 \cdot 17$ & C & 0.61 & 0.002 \\
\hline & Mean & $4.84^{\mathrm{a}}$ & $3 \cdot 12^{b}$ & $5 \cdot 31^{a}$ & 4.42 & $D \times C$ & 0.86 & 0.275 \\
\hline \multirow{3}{*}{ Liver total cholesterol ( $\mu \mathrm{mol} / /$ iver $)$} & Chow & 1.43 & 1.87 & 0.45 & 1.34 & $\mathrm{D}$ & 0.20 & $<0.001$ \\
\hline & $\mathrm{HF} / \mathrm{HC}$ & 14.35 & $12 \cdot 27$ & 13.87 & 13.57 & C & 0.25 & 0.240 \\
\hline & Mean & 7.99 & $7 \cdot 21$ & $7 \cdot 16$ & 7.45 & $D \times C$ & 0.35 & 0.738 \\
\hline
\end{tabular}

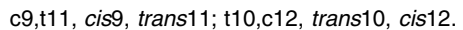

a,b Mean values within a row with unlike superscript letters were significantly different $(P<0.05)$.

${ }^{*}$ For details of procedures and diets, see Materials and methods.

† Statistical values were obtained by two-way ANOVA with background diet (D, chow or HF/HC) as one factor and CLA (C, none, c9,t11 or t10,c12) as a second factor. 

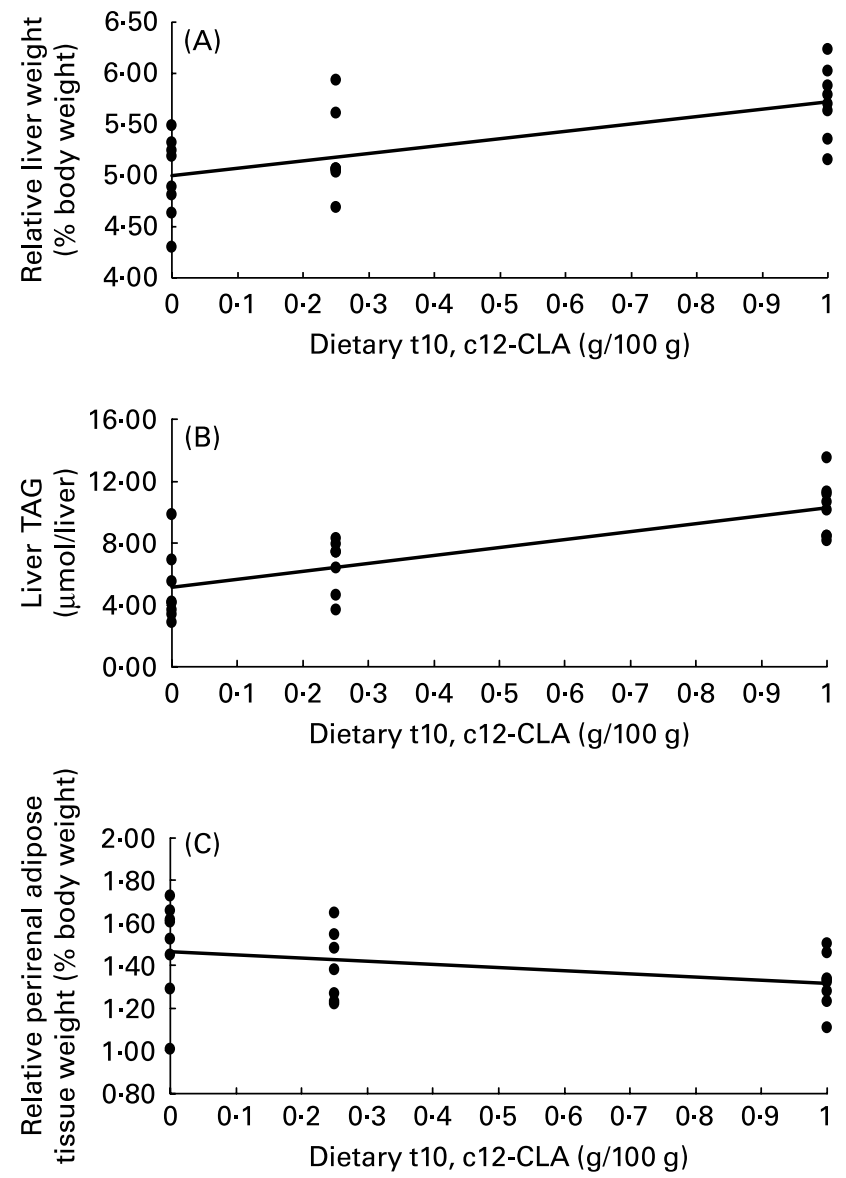

Fig. 1. Groups of eight hamsters were fed high-fat/high-cholesterol diet supplemented with $0.25 \%$ rapeseed oil, 0.25 or $1 \%$ trans 10 , cis 12 -conjugated linoleic acid. After 6 weeks animals were killed and the weight of liver (A) and perirenal adipose tissue (C) was recorded and expressed relative to total body weight. Liver lipids were extracted and TAG content determined (B). (A), $y=0.7235 x+5.0022, R^{2} 0.4293, P=0.001 ;(B), y=5.1197 x+5.1279$, $R^{2} 0.5845, P<0.001 ;(C), y=-0.1487 x+1.4652, R^{2} 0.1243, P=0.094$. acid in perirenal adipose tissue to 1.59 (SD 0.18 ) $\%$ and 1.24 (SD 0.06) \%, respectively. The t10,c12-CLA isomer was not detectable in the adipose tissue of animals fed the basal chow and high-fat diets. Supplementation of the two diets with this isomer increased tissue levels to 0.55 (SD 0.27) \% and 0.34 (SD 0.04)\%, respectively.

The $\mathrm{HF} / \mathrm{HC}$ diet caused a $17 \%$ increase in liver weight $(P<0 \cdot 001)$ which was associated with an accumulation of TAG and, particularly, cholesterol (Table 1). TLC confirmed that most of the cholesterol was in the esterified form (data not shown). Liver mass was also increased in animals fed t10,c12-CLA with the effect being more pronounced on a chow than a high-fat diet (18 v. $4 \%$ increase). Divergent effects of CLA isomers were seen on liver TAG levels with animals fed c9,t11-CLA having lower concentrations than either control or t10,c12-CLA-fed animals. In animals fed the $\mathrm{HF} / \mathrm{HC}$ diet there was a highly significant linear relationship between the amount of t10,c12-CLA in the diet and both relative liver weight (Fig. 1 (A)) and TAG content (Fig. 1 (B)). Hepatic cholesterol content was not affected by either dose of t10,c12-CLA.

\section{Effect on plasma lipids and lipoproteins}

The HF/HC diet significantly increased total plasma cholesterol $(P<0.001)$ and TAG $(P=0.015)$, however there were no further effects of CLA supplementation (Table 2). Both LDL and HDL cholesterol were increased by the HF/HC diet but again no effect of CLA supplementation was seen.

\section{Effect of diet on perirenal adipose tissue mRNA concentrations}

Feeding the HF/HC diet suppressed lipogenic gene expression in perirenal adipose tissue (Table 3 ) with levels of FAS, ACC and LPL mRNA all significantly reduced $(P<0.001)$. This was associated with reduced expression of each of the SREBP isoforms. While neither CLA isomer had any effect on FAS, or ACC mRNA, the t10,c12-CLA isomer specifically reduced perirenal adipose LPL mRNA by approximately $50 \%$

Table 2. Changes in blood lipid profile and liver lipids in hamsters fed a chow or high-fat/high-cholesterol (HF/HC) diet supplemented with $0.25 \%(\mathrm{w} / \mathrm{w})$ conjugated linoleic acid (CLA) isomers (eight animals per group) ${ }^{\star}$

\begin{tabular}{|c|c|c|c|c|c|c|c|c|}
\hline & & \multicolumn{4}{|c|}{ CLA } & \multicolumn{3}{|c|}{ ANOVAT } \\
\hline & & None & $\mathrm{c9}, \mathrm{t} 11$ & $\mathrm{t} 10, \mathrm{c} 12$ & Mean & & SED & $P$ \\
\hline \multirow[t]{3}{*}{ Total plasma cholesterol (mM) } & Chow & 3.53 & 3.54 & 3.09 & 3.39 & D & 0.18 & $<0.001$ \\
\hline & $\mathrm{HF} / \mathrm{HC}$ & 6.58 & $6 \cdot 39$ & 6.73 & 6.57 & C & 0.22 & 0.794 \\
\hline & Mean & 5.06 & 4.97 & 4.91 & 4.98 & $\mathrm{D} \times \mathrm{C}$ & 0.31 & 0.187 \\
\hline \multirow{3}{*}{ LDL cholesterol (mM) } & Chow & 0.23 & 0.24 & $0 \cdot 16$ & 0.21 & D & 0.06 & $<0.001$ \\
\hline & $\mathrm{HF} / \mathrm{HC}$ & 0.80 & 0.83 & 0.83 & 0.82 & C & 0.08 & 0.882 \\
\hline & Mean & 0.52 & 0.53 & 0.50 & 0.52 & $D \times C$ & 0.11 & 0.759 \\
\hline \multirow[t]{3}{*}{ HDL cholesterol (mM) } & Chow & $2 \cdot 27$ & 1.97 & $2 \cdot 17$ & $2 \cdot 14$ & D & 0.12 & $<0.001$ \\
\hline & $\mathrm{HF} / \mathrm{HC}$ & 3.08 & 3.08 & 3.34 & 3.16 & C & 0.15 & 0.284 \\
\hline & Mean & $2 \cdot 67$ & 2.52 & $2 \cdot 76$ & $2 \cdot 65$ & $\mathrm{D} \times \mathrm{C}$ & 0.21 & 0.430 \\
\hline \multirow[t]{3}{*}{ Plasma TAG (mM) } & Chow & 1.26 & 1.30 & 1.44 & 1.33 & D & 0.13 & 0.015 \\
\hline & $\mathrm{HF} / \mathrm{HC}$ & 1.95 & 1.55 & 1.46 & 1.65 & C & 0.15 & 0.424 \\
\hline & Mean & 1.61 & 1.42 & 1.45 & 1.49 & $\mathrm{D} \times \mathrm{C}$ & 0.22 & 0.094 \\
\hline
\end{tabular}

$\mathrm{c} 9, \mathrm{t} 11, \mathrm{cis} 9$, trans11; $\mathrm{t} 10, \mathrm{c} 12$, trans 10, cis 12 .

${ }^{*}$ For details of procedures and diets, see Materials and methods.

† Statistical values were obtained by two-way ANOVA with background diet ( $\mathrm{D}$, chow or HF/HC) as one factor and CLA (C, none, c9,t11 or t10,c12) as a second factor. 
Table 3. Changes in gene expression in perirenal adipose as a result of feeding either a chow or a high-fat/high-cholesterol (HF/HC) diet supplemented with $0.25 \%(w / w)$ conjugated linoleic acid (CLA) isomers (eight animals per group)*

\begin{tabular}{|c|c|c|c|c|c|c|c|c|}
\hline & & \multicolumn{4}{|c|}{ CLA } & \multicolumn{3}{|c|}{ ANOVAT } \\
\hline & & None & $\mathrm{c} 9, \mathrm{t} 11$ & $\mathrm{t} 10, \mathrm{c} 12$ & Mean & & SED & $P$ \\
\hline \multirow[t]{3}{*}{ ACC } & Chow & 1.70 & 1.43 & 1.87 & 1.67 & D & 0.16 & $<0.001$ \\
\hline & $\mathrm{HF} / \mathrm{HC}$ & 0.81 & 0.62 & 0.58 & 0.69 & C & $0 \cdot 19$ & 0.533 \\
\hline & Mean & 1.25 & 1.05 & 1.23 & $1 \cdot 18$ & $\mathrm{D} \times \mathrm{C}$ & 0.27 & 0.371 \\
\hline \multirow[t]{3}{*}{ FAS } & Chow & 1.79 & 1.93 & 1.55 & 1.76 & D & 0.18 & 0.001 \\
\hline & $\mathrm{HF} / \mathrm{HC}$ & 0.72 & 0.83 & 0.45 & 0.66 & C & 0.22 & 0.227 \\
\hline & Mean & 1.25 & 1.38 & 1.00 & 1.21 & $\mathrm{D} \times \mathrm{C}$ & 0.31 & 0.995 \\
\hline \multirow[t]{3}{*}{ LPL } & Chow & $1 \cdot 78$ & 1.51 & 0.96 & 1.41 & D & 0.14 & $<0.001$ \\
\hline & $\mathrm{HF} / \mathrm{HC}$ & 1.00 & 1.14 & 0.53 & 0.89 & C & 0.17 & $<0.001$ \\
\hline & MEAN & $1.39^{\mathrm{a}}$ & $1.32^{\mathrm{a}}$ & $0.74^{\mathrm{b}}$ & $1 \cdot 15$ & $\mathrm{D} \times \mathrm{C}$ & 0.24 & 0.427 \\
\hline \multirow[t]{3}{*}{ SREBP-1a } & Chow & 1.63 & $1 \cdot 25$ & 1.43 & 1.44 & D & 0.14 & $<0.001$ \\
\hline & $\mathrm{HF} / \mathrm{HC}$ & 0.88 & 1.23 & 0.69 & 0.94 & C & 0.17 & 0.429 \\
\hline & Mean & $1 \cdot 26$ & $1 \cdot 24$ & 1.06 & $1 \cdot 19$ & $\mathrm{D} \times \mathrm{C}$ & 0.24 & 0.056 \\
\hline \multirow{3}{*}{ SREBP-1C } & Chow & 1.66 & 1.55 & 1.27 & 1.49 & D & 0.14 & 0.003 \\
\hline & $\mathrm{HF} / \mathrm{HC}$ & $1 \cdot 14$ & $1 \cdot 32$ & 0.64 & 1.03 & C & 0.18 & 0.018 \\
\hline & Mean & $1.40^{\mathrm{a}}$ & $1.44^{\mathrm{a}}$ & $0.96^{\mathrm{b}}$ & 1.26 & $\mathrm{D} \times \mathrm{C}$ & 0.25 & 0.513 \\
\hline \multirow[t]{3}{*}{ SREBP-2 } & Chow & 1.44 & $1 \cdot 27$ & $1 \cdot 19$ & $1 \cdot 30$ & $\mathrm{D}$ & 0.15 & $<0.001$ \\
\hline & $\mathrm{HF} / \mathrm{HC}$ & 0.97 & 0.77 & 0.50 & 0.75 & C & 0.18 & 0.154 \\
\hline & Mean & $1 \cdot 21$ & 1.02 & 0.84 & 1.02 & $\mathrm{D} \times \mathrm{C}$ & 0.26 & 0.803 \\
\hline
\end{tabular}

ACC, acetyl CoA carboxylase; $c 9,111$, cis9, trans11; FAS, fatty acid synthase; LPL, lipoprotein lipase; SREBP, sterol regulatory element binding protein; t10,c12, trans10, cis12. $\mathrm{a}, \mathrm{b}$ Mean values within a row with unlike superscript letters were significantly different $(P<0.05)$.

${ }^{*}$ For details of procedures and diets, see Materials and methods. Data are expressed in arbitrary units relative to $\beta$-actin mRNA.

† Statistical values were obtained by two-way ANOVA with background diet ( $\mathrm{D}$, chow or HF/HC) as one factor and CLA (C, none, c9,t11 or t10,c12) as a second factor.

irrespective of background diet. SREBP-1c mRNA levels were also reduced, by approximately $30 \%$, by t10,c12-CLA independently of background diet.

\section{Effect of diet on hepatic mRNA concentrations}

FAS and ACC mRNA levels were decreased, but LPL mRNA concentration was increased, by the $\mathrm{HF} / \mathrm{HC}$ diet (Table 4; $P=0 \cdot 001)$. Consumption of the $\mathrm{HF} / \mathrm{HC}$ diet was associated with a decrease in expression of hepatic LDLr and SREBP-2 and an increase in ABC-A1 mRNA expression $(P<0.001)$. However, no effect of the $\mathrm{HF} / \mathrm{HC}$ diet was observed on the levels of either SREBP-1a or -1c transcripts in the liver. In contrast with the perirenal tissue, none of the mRNA measured in the liver were affected by CLA consumption. Within liver ACC, FAS and LDLr mRNA were all positively correlated to SREBP-2 mRNA but were not related to either SREBP-1c or -1a mRNA (Table 5). LPL mRNA was positively correlated with ABC-A1 mRNA which in turn was correlated with SREBP-1c mRNA.

\section{Discussion}

Initial observations that CLA reduced adipose tissue deposition were originally performed in mice fed high-carbohydrate/low-fat diets ${ }^{(7,9)}$. It is now quite clear that under these conditions, in this species, CLA induces a lipoatrophic syndrome $^{(9)}$ in which dramatic adipose tissue loss is associated with severe hyperinsulinaemia, insulin resistance and hepatic steatosis. More recently, a number of studies have been performed in the Golden Syrian Hamster. In general these studies have explored the impact of CLA isomers against a background of $\mathrm{HF} / \mathrm{HC}$ diets. Thus, one of the aims of the present study was to explore effects on both low- and high-fat diets.
The majority of previous hamster studies have fed highly saturated plant oils as the only source of dietary fat. For example, Portillo and colleagues ${ }^{(12,13,15,18,21)}$ use semi-synthetic diets supplemented with $10 \%$ palm oil. As a result, total food energy from fat was approximately $22 \%$ and that from $n-6$ PUFA only about $3 \%$. This contrasts with typical intakes in many industrialized countries of over $35 \%$ energy from total fat and 5-6\% from n-6 PUFA ${ }^{(26)}$. Hayes et al. ${ }^{(27)}$ have suggested that the responsiveness of animals to changes in fatty acid composition of the diet is exaggerated at low $n-6$ PUFA intakes. In many previous studies this may be further confounded by the fact that the effect of CLA isomers is directly compared to diets supplemented with equivalent amounts of linoleic acid. For example, Navarro et al. ${ }^{(12)}$ showed that adipose tissue mass (epididymal and perirenal) were not significantly different in hamster fed chow compared to those fed a semi-purified diet containing $0.5 \%$ t10,c12CLA. However, when compared to a semi-synthetic diet containing $0.5 \%$ high-linoleic acid sunflower oil, adipose tissue weights were significantly lower in both the chow-fed animals and those consuming the semi-synthetic diet supplemented with t10,c12-CLA. It is difficult to ascertain whether the changes seen in such studies are a result of CLA or reduced linoleic acid in the diet. In the present study high-fat diets were designed to mimic a 'Western' diet in terms of both fatty acid composition and quantity. The high-fat diet used provided approximately $44 \%$ of energy from total fat and 5.6\% from n-6 PUFA, intakes which would not be uncommon in a human 'Western' diet. Supplementation with CLA isomers has been compared to that with high-oleic acid rape seed oil.

Previous studies of the effects of CLA on lipid metabolism in hamsters have used CLA intakes of $0 \cdot 5-1 \%(\mathrm{w} / \mathrm{w})^{(11-23)}$. Based on typical food intakes and body weights this represents 
Table 4. Changes in gene expression in the liver as a result of feeding either a chow or a high-fat/high-cholesterol (HF/HC) diet supplemented with $0.25 \%(w / w)$ conjugated linoleic acid (CLA) isomers (eight animals per group) ${ }^{\star}$

\begin{tabular}{|c|c|c|c|c|c|c|c|c|}
\hline & & \multicolumn{4}{|c|}{ CLA } & \multicolumn{3}{|c|}{ ANOVA† } \\
\hline & & None & $\mathrm{c} 9, \mathrm{t} 11$ & $\mathrm{t} 10, \mathrm{c} 12$ & Mean & & SED & $P$ \\
\hline \multirow[t]{3}{*}{ LDLr } & Chow & 1.81 & 1.49 & 1.17 & 1.49 & D & 0.13 & $<0.001$ \\
\hline & $\mathrm{HF} / \mathrm{HC}$ & 0.42 & 0.54 & 0.34 & 0.43 & C & 0.16 & 0.082 \\
\hline & Mean & $1 \cdot 11$ & 1.01 & 0.75 & 0.96 & $\mathrm{D} \times \mathrm{C}$ & 0.23 & 0.199 \\
\hline \multirow[t]{3}{*}{ ACC } & Chow & 1.56 & 1.27 & $1 \cdot 35$ & 1.40 & D & 0.13 & 0.001 \\
\hline & $\mathrm{HF} / \mathrm{HC}$ & 0.49 & 0.77 & 0.38 & 0.54 & C & 0.16 & 0.515 \\
\hline & Mean & 1.02 & 1.02 & 0.87 & 0.97 & $\mathrm{D} \times \mathrm{C}$ & 0.22 & 0.159 \\
\hline \multirow[t]{3}{*}{ FAS } & Chow & 1.77 & 1.53 & 1.55 & 1.61 & D & 0.15 & $<0.001$ \\
\hline & $\mathrm{HF} / \mathrm{HC}$ & 0.37 & 0.70 & 0.36 & 0.47 & C & 0.18 & 0.647 \\
\hline & Mean & 1.06 & $1 \cdot 12$ & 0.95 & 1.04 & $\mathrm{D} \times \mathrm{C}$ & 0.25 & 0.280 \\
\hline \multirow[t]{3}{*}{ LPL } & Chow & 0.56 & 0.54 & 0.46 & 0.52 & D & 0.17 & $<0.001$ \\
\hline & $\mathrm{HF} / \mathrm{HC}$ & 1.81 & 1.52 & 1.89 & 1.74 & C & 0.21 & 0.695 \\
\hline & Mean & $1 \cdot 19$ & 1.03 & $1 \cdot 18$ & 1.13 & $\mathrm{D} \times \mathrm{C}$ & 0.30 & 0.569 \\
\hline \multirow{3}{*}{ SREBP-1a } & Chow & 1.14 & 1.62 & 1.24 & 1.34 & D & 0.14 & 0.154 \\
\hline & $\mathrm{HF} / \mathrm{HC}$ & 1.24 & $1 \cdot 21$ & 1.05 & 1.17 & C & 0.17 & 0.203 \\
\hline & Mean & $1 \cdot 19$ & 1.41 & $1 \cdot 15$ & 1.25 & $\mathrm{D} \times \mathrm{C}$ & 0.24 & 0.493 \\
\hline \multirow[t]{3}{*}{ SREBP-1C } & Chow & $1 \cdot 14$ & $1 \cdot 19$ & 1.30 & 1.21 & D & 0.11 & 0.587 \\
\hline & $\mathrm{HF} / \mathrm{HC}$ & 1.07 & 1.30 & 1.07 & $1 \cdot 15$ & C & 0.14 & 0.569 \\
\hline & Mean & $1 \cdot 10$ & 1.25 & $1 \cdot 18$ & 1.18 & $\mathrm{D} \times \mathrm{C}$ & 0.19 & 0.458 \\
\hline \multirow[t]{3}{*}{ SREBP-2 } & Chow & 2.32 & 2.06 & 1.57 & 1.98 & D & 0.21 & $<0.001$ \\
\hline & $\mathrm{HF} / \mathrm{HC}$ & 0.72 & 1.37 & 0.83 & 0.97 & C & 0.25 & 0.133 \\
\hline & Mean & 1.52 & 1.71 & 1.20 & 1.48 & $\mathrm{D} \times \mathrm{C}$ & 0.35 & 0.137 \\
\hline \multirow[t]{3}{*}{$A B C-A 1$} & Chow & 0.81 & 1.00 & 0.80 & 0.87 & $\mathrm{D}$ & 0.12 & $<0.001$ \\
\hline & $\mathrm{HF} / \mathrm{HC}$ & 1.39 & 1.49 & 1.36 & 1.41 & C & 0.14 & 0.447 \\
\hline & Mean & $1 \cdot 10$ & 1.24 & 1.08 & 1.14 & $\mathrm{D} \times \mathrm{C}$ & 0.20 & 0.940 \\
\hline
\end{tabular}

ABC-A1, ATP binding cassette transporter A1; ACC, acetyl CoA carboxylase; c9,t11, cis9, trans11; FAS, fatty acid synthase; LDLr, LDL receptor; LPL, lipoprotein lipase; SREBP, sterol regulatory element binding protein; t10,c12, trans10, cis12.

* For details of procedures and diets, see Materials and methods. Data are expressed in arbitrary units relative to $\beta$-actin mRNA.

†Statistical values were obtained by two-way ANOVA with background diet (D, chow or HF/HC) as one factor and CLA (C, none, c9,t11 or t10,c12) as a second factor.

a daily intake of approximately $30-60 \mathrm{mg}$ CLA/d or $250-500 \mathrm{mg} / \mathrm{kg}$ body weight per $\mathrm{d}$. This would translate to an intake of $20-40 \mathrm{~g} / \mathrm{d}$ in an $80 \mathrm{~kg}$ man, which would be clearly unachievable. Alternatively, intake can be expressed as a proportion of total energy intake. Based on an energy content of normal laboratory chow of about $10 \mathrm{~kJ} / \mathrm{g}$, these levels of supplementation with CLA would represent an approximate intake of $0 \cdot 5-1 \mathrm{mg}$ CLA/kJ. To obtain a similar dose, a man consuming $10 \mathrm{MJ} / \mathrm{d}$ would need to consume 5-10 g CLA/d. It remains to be established which of these estimations is most appropriate and this probably depends on the extent to which effects are dependent on the accumulation of CLA in the tissue. The amount of CLA used in the present study was approximately equivalent to a human intake of $10 \mathrm{~g} / \mathrm{d}$ (on a body weight basis) or $2.5 \mathrm{~g} / \mathrm{d}$ on an energy intake basis. While still high, this is approaching more achievable human supplementation levels.

As we have previously shown, the $\mathrm{HF} / \mathrm{HC}$ diet increased plasma cholesterol and $\mathrm{TAG}^{(28,29)}$. While both $\mathrm{LDL}$ and HDL cholesterol were increased, the effect on the former was more significant, resulting in an increase in the ratio of LDL to HDL from $0 \cdot 1$ to $0 \cdot 25$. As previously reported ${ }^{(28,29)}$, cholesterol-feeding was also associated with increased hepatic cholesterol ester concentration and a more modest elevation in hepatic TAG. Also, as previously seen, hepatic LDLr mRNA concentrations were reduced by the HF/HC $\operatorname{diet}^{(29)}$. LDLr expression has been shown to be largely regulated by the activity of SREBP- $2^{(30)}$ and indeed there was a

Table 5. Correlation matrices for mRNA concentrations in liver $\dagger$

(Correlation coefficients)

\begin{tabular}{|c|c|c|c|c|c|c|c|}
\hline & ACC & FAS & LPL & LDLr & ABC-A1 & SREBP-1a & SREBP-1C \\
\hline FAS & $0.962^{\star \star \star}$ & & & & & & \\
\hline LPL & $-0.542^{\star \star \star}$ & $-0.618^{\star \star \star}$ & & & & & \\
\hline LDLr & $0.672^{\star \star \star}$ & $0.698^{\star \star \star}$ & $-0.615^{\star \star \star}$ & & & & \\
\hline$A B C-A 1$ & $-0.339^{*}$ & $-0.419^{\star \star}$ & $0.824^{\star * \star}$ & $-0.382^{\star *}$ & & & \\
\hline SREBP-1a & 0.271 & 0.253 & -0.168 & $0.418^{\star *}$ & 0.036 & & \\
\hline SREBP-1c & $0.379^{*}$ & 0.283 & 0.053 & 0.203 & $0.450^{* *}$ & $0.385^{\star \star}$ & \\
\hline SREBP-2 & $0.626^{\star \star *}$ & $0.694^{* * *}$ & $-0.453^{\star \star}$ & $0.691^{\star \star \star}$ & $-0.317^{\star}$ & 0.151 & 0.002 \\
\hline
\end{tabular}

ABC-A1, ATP binding cassette transporter A1; ACC, acetyl CoA carboxylase; FAS, fatty acid synthase; LDLr, LDL receptor; LPL, lipoprotein lipase; SREBP, sterol regulatory element binding protein.

${ }^{\star} P<0.05,{ }^{* *} P<0.01,{ }^{* * \star} P<0.001$.

$\dagger$ For details of procedures, see Materials and methods. 
highly significant correlation between SREBP-2 and LDLr mRNA concentrations $(P<0 \cdot 001)$. This diet also had marked effects on adipose tissue and hepatic lipogenic gene expression. ACC and FAS mRNA concentrations were reduced in both tissues while LPL was reduced in adipose tissue but increased in liver. Lipogenic gene expression is regulated by the activity of $\operatorname{SREBP}^{(30)}$ and expression of all three isoforms was reduced in adipose tissue. In liver, however, only SREBP-2 mRNA was reduced. While it has long been suggested that the expression of lipogenic genes such as ACC and FAS are primarily regulated by SREBP-1 isoforms, there is evidence to suggest that SREBP-2 may also play a role ${ }^{(31,32)}$. In fact, this isoform is a much more potent regulator of gene transcription than SREBP-1c (the major SREBP-1 isoform in liver) ${ }^{(33)}$. In view of a highly significant correlation between hepatic SREBP-2 mRNA and both ACC $(P<0.001)$ and FAS $(P<0.001)$, it is interesting to speculate that the reduction in SREBP-2 is responsible for the reduction in expression of these two genes. However, it is also possible that nuclear concentrations of SREBP-1c mature protein are decreased in the absence of changes in gene expression. LPL mRNA showed tissue-specific responses to the HF/HC diet. In adipose tissue, LPL expression was down-regulated and showed a high degree of correlation with ACC, FAS and each of the SREBP. However, in liver it was actually up-regulated and showed negative associations with ACC, FAS and SREBP-2. LPL has been shown to contain a sterol regulatory element within its promoter and therefore might have been expected to change in the same direction as ACC and $\mathrm{FAS}^{(34)}$. However, it has also been reported to contain response elements for the liver $\mathrm{X}$ receptor ${ }^{(35)}$. Liver $\mathrm{X}$ receptor $\alpha$ is a nuclear receptor that is activated by oxygenated derivatives of cholesterol and is known to regulate the expression of a range of genes for enzymes and other proteins involved in cholesterol and lipid metabolism ${ }^{(36)}$. It is possible that the increased cholesterol content of the diets has led to the generation of increased liver $\mathrm{X}$ receptor ligand(s) and this may, in turn, lead to the up-regulation of LPL gene expression. The highly significant correlation between ABC-A1 mRNA and LPL mRNA supports this hypothesis. ABC-A1 is well established as a target gene for liver $\mathrm{X}$ receptor ${ }^{(37)}$. However, it is of note that ACC and FAS have both been reported to have liver $\mathrm{X}$ receptor response elements within their promoters $^{(38,39)}$, and we observed negative correlations in expression of these genes relative to $\mathrm{ABC}-\mathrm{A} 1$. How $\mathrm{HF} / \mathrm{HC}$ diets mediate such divergent effects on these genes warrants further investigation.

Work in mice has shown that t10,c12-CLA dramatically reduces adipose tissue deposition ${ }^{(7,9)}$. Recent studies in hamsters have indicated more modest effects on adipose tissue $\operatorname{mass}^{(10,11,18,23,40)}$. In the present study, the t10,c12-CLA isomer also modestly reduced perirenal, but not epididymal adipose tissue mass. It is of note that even when fed at $1 \%$, t10,c12-CLA (as part of a HF/HC diet) failed to reduce epipidymal fat mass and no dose-dependent effect was seen on the perirenal depot weight. The effect of t10,c12-CLA on perirenal fat was associated with a reduction in LPL mRNA level, which was decreased by up to almost $50 \%$ irrespective of the background diet. The t10,c12-CLA isomer also reduced SREBP-1c mRNA concentrations in the perirenal adipose, and potentially represents the mechanism by which t10,c12-CLA is affecting perirenal LPL mRNA levels. This is supported by a highly significant correlation between LPL and SREBP-1c mRNA levels in perirenal adipose. Zabala et $a l .{ }^{(18)}$ found that 0.5 and $1 \%$ t10,c12-CLA reduced the mass of epididymal, perirenal and subcutaneous fat depots. The reduction in epididymal fat mass was also shown to be associated with reduced LPL mRNA concentration and enzyme activity. They also demonstrated reduced SREBP-1c expression, though in this case SREBP-1a was also reduced. It is not clear why no effect on epididymal fat mass was seen in the current experiment. However, it is of note that while Zabala et al. ${ }^{(18)}$ were substituting linoleic acid-rich oil with CLA, in the current experiment oleic acid-rich rapeseed oil was used. Another difference in the findings of these two studies was that while Zabala et al. ${ }^{(18)}$ found ACC and FAS expression was reduced in epididymal adipose tissue, in the present experiment these were not affected by t10,c12-CLA in the perirenal depot. The differences in findings between these two studies, depot-specific responses and impact of altering the linoleic acid content of the diets are all worthy of further study.

In the present study we found no evidence of an effect of either CLA isomer on plasma total, LDL or HDL cholesterol, on either background diet. Previous work in the hamster has produced conflicting results. We have previously reported reduced LDL cholesterol levels in hamsters fed butter enriched in c9,t11CLA and t11-18: $1^{(17)}$. While one group has reported reduced LDL in hamsters fed pure c9,t11-CLA ${ }^{(22)}$, others have found no effect ${ }^{(10,12,16)}$. The results of studies using pure t10,c12CLA have also produced a range of effects with some authors reporting decreases in LDL cholesterol ${ }^{(10,12)}$, one showing an increase $^{(19)}$ and others reporting no effect ${ }^{(16,22)}$. The response of HDL cholesterol to pure isomers has been equally varied with some reports of increased HDL with c9,t11-CLA ${ }^{(41)}$ and $\mathrm{t} 10, \mathrm{c} 12-\mathrm{CLA}^{(16)}$ and other reports suggesting decreases ${ }^{(10,20)}$ or no effect ${ }^{(12,17)}$. The variability in responses is likely to be a combination of factors including differences in dose of CLA, background diet and age/strain of hamster. It is of note that in man no significant effect of supplementation with either CLA isomer was seen when compared to pre-supplementation levels. There was, however, some suggestion of a divergent effect of the two isomers, with c9,t11-CLA decreasing and t10,c12-CLA increasing the ratio of LDL cholesterol to HDL cholesterol $^{(42)}$. Taken together the data suggest that any effects of CLA using dosages achievable in man will be small.

The t10,c12-CLA isomer increased liver weight in a dose-dependent manner. This is consistent with a number of other hamster studies using concentrations of CLA of $0 \cdot 5-1 \%{ }^{(10-12,15,20)}$. Previous workers ${ }^{(15)}$ have suggested that the increase in liver weight is associated with an increase in the number of hepatocytes within the livers of animals fed the t10,c12 isomer. At low concentrations we also found divergent effects of the isomers on liver TAG, with c9, t11-CLA tending to reduce and t10,c12-CLA increase, concentrations. This concurs with previous findings ${ }^{(43)}$ which demonstrated divergent effects of these CLA isomers on the level of liver steatosis in apoE knockout mice. One possible theory offered by those authors for the effect is that the c9,t11-CLA may preferentially promote lipolysis in the liver by PPAR $\alpha$ activation. Hepatic TAG increased linearly with dose of t10,c12-CLA, with a doubling of the amount in 
livers from animals fed $1 \%$ t10,c12-CLA. It remains to be established whether feeding a mixture of c9,t11-CLA and t10,c12-CLA will offset the steatosis associated with intake of the latter.

Overall the present data suggest low dose supplements with c9,t11-CLA have little impact on lipid metabolism in the hamster irrespective of whether this is fed against the background of a high carbohydrate, lipogenic diet or a $\mathrm{HF} / \mathrm{HC}$ diet. The apparent effect of this isomer in reducing liver TAG is worthy of further investigation as it may potentially offset the steatosis induced by the $t 10, \mathrm{c} 12$ isomer when mixed isomer preparations are fed. The t10,c12-CLA isomer reduced the size of the perirenal adipose tissue depot, and this is associated with reduced adipose tissue LPL expression which may be the result of reduced SREBP-1c expression. However, this was also associated with hepatomegaly and increased hepatic TAG accumulation. The study also highlights important differences in the expression of lipogenic genes in response to $\mathrm{HF} / \mathrm{HC}$ cholesterol diets and tissuespecific differences in these responses.

\section{Acknowledgements}

The authors would like to acknowledge the excellent technical assistance of Mr Richard Plant and Mr David Bozon. This work was funded by a studentship to E. J. T. and a project grant from the UK BBSRC. The authors have no conflicts of interest to declare. E. J. T. and K. J. P. R. performed the majority of the laboratory work and contributed to the analysis of data and the writing of the manuscript. A. J. B. was a co-investigator and grant holder and played a significant role in the design of the study, interpretation of results and writing of the manuscript. A. M. S. was the principle investigator and grant holder and played a major role in the design and performance of the study, analysis and interpretation of the results and the writing of the paper.

\section{References}

1. Pariza MW (2004) Perspective on safety and effectiveness of conjugated linoleic acid. Am J Cin Nutr 79, 1132S-1136S.

2. Bhattacharya A, Banu J, Rahman M, et al. (2006) Biological effects of conjugated linoleic acids in health and disease. J Nutr Biochem 17, 789-810.

3. Wahle KW, Hey SD \& Rotondo D (2004) Conjugated linoleic acids: are they beneficial or detrimental to health. Prog Lipid Res 43, 553-587.

4. Kelly NS, Hubbard NE \& Erickson KL (2007) Conjugated linoleic acid isomers and cancer. J Nutr 137, 2599-2607.

5. Whigham LD, Watras AC \& Schoeller DA (2007) Efficacy of conjugated linoleic acid for reducing fat mass: a meta-analysis in humans. Am J Clin Nutr 85, 1203-1211.

6. Griinari JM, Corl BA, Lacy SH, et al. (2000) Conjugated linoleic acid is synthesized endogenously in lactating dairy cows by $\Delta$ 9-desaturase. J Nutr 130, 2285-2291.

7. Park Y, Storkson JM, Albright KJ, et al. (1999) Evidence that trans-10, cis-12 isomer of conjugated linoleic acid induces body composition changes in mice. Lipids 34, 235-241.

8. Ip C, Banni S, Angioni E, et al. (1999) Conjugated linoleic acidrich butter fat alters mammary gland morphogenesis and reduces cancer risk in rats. $J$ Nutr 129, 2135-2142.
9. Poirier H, Niot I, Clément L, et al. (2005) Development of conjugated linoleic acid (CLA)-mediated lipoatrophic syndrome in the mouse. Biochimie 87, 73-79.

10. DeDeckere EAM, van Amelsvoort JMM, McNeill GP, et al. (1999) Effects of conjugated linoleic acid (CLA) isomers on lipid levels and peroxisome proliferation in the hamster. $\mathrm{Br} J$ Nutr 82, 309-317.

11. Gavino VC, Gavino G, Leblanc M-J, et al. (2000) An isomeric mixture of conjugated linoleic acids but not pure cis-9,trans-11octadecadienoic acid affects body weight gain and plasma lipids in hamsters. J Nutr 130, 27-29.

12. Navarro V, Zabala A, Marcarulla MT, et al. (2003) Effects of conjugated linoleic acid on body fat accumulation and serum lipids in hamsters fed an atherogenic diet. J Physiol Biochem 59, 193-200.

13. Zabala A, Churruca I, Marculla MT, et al. (2004) The trans-10, cis-12 isomer of conjugated linoleic acid reduces hepatic triacylglycerol content without affecting lipogenic enzymes in hamsters. Br J Nutr 92, 383-389.

14. Valeille K, Férézou J, Amsler G, et al. (2005) A cis-9, trans-11conjugated linoleic acid-rich oil reduces the outcome of atherogenic process in hyperlipidemic hamster. Am J Physiol Heart Circ Physiol 289, H652-H659.

15. Macarulla MT, Fernández-Quintela A, Zabala A, et al. (2005) Effects of conjugated linoleic acid on liver composition and fatty acid oxidation are isomer-dependent in hamster. Nutrition 21, 512-519.

16. Mitchell PL, Langille MA, Currie DL, et al. (2005) Effect of conjugated linoleic acid isomers on lipoproteins and atherosclerosis in the Syrian Golden hamster. Biochim Biophys Acta 1734, 269-276.

17. Lock AL, Horne CAM, Bauman DE, et al. (2005) Butter naturally enriched in conjugated linoleic acid and vaccenic acid alters tissue fatty acids and improves the plasma lipoprotein profile in cholesterol-fed hamsters. J Nutr 135, 1934-1939.

18. Zabala A, Churruca I, Fernández-Quintela A, et al. (2006) trans-10, cis-12 Conjugated linoleic acid inhibits lipoprotein lipase but increases the activity of lipogenic enzymes in adipose tissue from hamsters fed an atherogenic diet. Br J Nutr 95, 1112-1119.

19. Bissonauth V, Chouinard Y, Marin J, et al. (2006) The effects of $t 10, c 12$ CLA isomer compared with $c 9, t 11$ CLA isomer on lipid metabolism and body composition in hamsters. J Nutr Biochem 17, 597-603.

20. Wilson TA, Nicolsi RJ, Saati A, et al. (2006) Conjugated linoleic acid isomers reduce blood cholesterol levels but not aortic cholesterol accumulation in hypercholesterolemic hamsters. Lipids 41, 41-48.

21. Zabala A, Portillo MP, Macarulla MT, et al. (2006) Effects of cis-9, trans-11 and trans-10, cis-12 CLA isomers on liver and adipose tissue fatty acid profile in hamsters. Lipids 41, 993-1001.

22. LeDoux M, Laloux L, Fontaine J-J, et al. (2007) Rumenic acid significantly reduces plasma levels of LDL and small dense LDL cholesterol in hamsters fed a cholesterol- and lipidenriched semi-purified diet. Lipids 42, 135-141.

23. Ribot J, Portillo MP \& Picó C, et al. (2007) Effects of trans-10, cis12 conjugated linoleic acid on the expression of uncoupling proteins in hamsters fed an atherogenic diet. Br J Nutr 97, 1074-1082.

24. Salter AM, Mangiapane EH, Bennett AJ, et al. (1998) The effect of different dietary fatty acids on lipoprotein metabolism: concentration-dependent effects of diets enriched in oleic, myristic, palmitic and stearic acids. Br J Nutr 79, 195-202.

25. Major CA, Ryan K, Bennett AJ, et al. (2008) Inhibition of stearoyl coenzyme A desaturase activity induces hypercholesterolemia in the cholesterol-fed hamster. J Lipid Res 49, 1456-1465.

26. Henderson L, Gregory J, Irving K, et al. (2003) The National Diet \& Nutrition Survey: Adults Aged 10 to 64 Years, vol. 2, pp. 53-57. London: TSO. 
27. Hayes KC, Pronczuk A \& Khosla P (1995) A rationale for plasma cholesterol modulation by dietary fatty acids: modeling the human response in animals. J Nutr Biochem 6, 188-194.

28. Session VA \& Salter AM (1994) The effects of different dietary fats and cholesterol on serum lipoprotein concentrations in hamsters. Biochim Biophys Acta 1211, 207-214.

29. Billett MA, Bruce JS, White DA, et al. (2000) Interactive effects of dietary cholesterol and different saturated fatty acids on lipoprotein metabolism. Br J Nutr 84, 439-447.

30. Horton JD, Goldstein JL \& Brown MS (2002) SREBPs: activators of the complete program of cholesterol and fatty acid synthesis in the liver. J Clin Invest 109, 1125-1131.

31. Magana MM \& Osborne TF (1996) Two tandem binding sites for sterol regulatory element binding proteins are required for sterol regulation of fatty-acid synthase promoter. $J$ Biol Chem 271, 32689-32694.

32. Bennett MK, Toth JI \& Osborne TF (2004) Selective association of sterol regulatory element-binding protein isoforms with target promoters in vivo. J Biol Chem 279, 37360-37367.

33. Amemiya-Kudo M, Shimano H, Hasty AH, et al. (2002) Transcriptional activities of nuclear SREBP-1a, $-1 \mathrm{c}$, and -2 to different target promoters of lipogenic and cholesterogenic genes. J Lipid Res 43, 1220-1235.

34. Schoonjans K, Gelman L, Haby C, et al. (2000) Induction of LPL gene expression by sterols is mediated by a sterol regulatory element and is independent of the presence of multiple $\mathrm{E}$ boxes. J Mol Biol 304, 323-334.

35. Zhang Y, Repa JJ, Gauthier K, et al. (2001) Regulation of lipoprotein lipase by the oxysterol receptors LXR $\alpha$ and LXR $\beta$. J Biol Chem 276, 43018-43024.
36. Lehmann JM, Kliewer SA, Moore LB, et al. (1997) Activation of the nuclear receptor LXR $\alpha$ by oxysterols defines a new hormone response pathway. J Biol Chem 272, 3137-3140.

37. Costet P, Luo Y, Wang N, et al. (2000) Sterol-dependent transactivation of the the $\mathrm{ABC} 1$ promoter by the liver $\mathrm{X}$ receptor/ retinoid X receptor. J Biol Chem 275, 28240-28245.

38. Talukdar S \& Hillgartner FB (2006) The mechanism mediating the activation of acetyl-coenzyme A carboxylase-alpha gene transcription by the liver $\mathrm{X}$ receptor agonist T0-901317. $J$ Lipid Res 47, 2451-2461.

39. Joseph SB, Laffitte BA, Patel PH, et al. (2002) Direct and indirect mechanisms for regulation of fatty acid synthase gene expression by liver X receptors. J Biol Chem 277, 11019-11025.

40. Simón E, Macarulla MT, Churruca I, et al. (2006) Trans-10,cis12 Conjugated linoleic acid prevents adiposity but not insulin resistance induced by an atherogenic diet in hamsters. $J$ Nutr Biochem 17, 126-131.

41. Valeille K, Gripois D, Blouquit M-F, et al. (2004) Lipid atherogenic risk markers can be more favourably influenced by cis-9,trans-11-octadecadienoate isomer than a conjugated linoleic acid mixture or fish oil in hamsters. Br J Nutr 91, 191-199.

42. Tricon S, Burdge GC, Kew S, et al. (2004) Opposing effects of cis-9,trans-11 and trans-10,cis-12 conjugated linoleic acid on blood lipids in healthy humans. Am J Clin Nutr 80, 614-620.

43. Arbonés-Mainar JM, Navarro MA, Acín S, et al. (2006) Trans10, cis-12- and cis-9, trans-11-conjugated linoleic acid isomers selectively modify HDL-apolipoprotein composition in apolipoprotein E knockout mice. J Nutr 136, 353-359. 